Fetal Diagnosis and Therapy
Fetal Diagn Ther 2012;32:231-238

DOI: $\underline{10.1159 / 000339480}$
Received: March 6, 2012

Accepted after revision: April 27, 2012

Published online: September 25, 2012

\title{
Maternal Hemodynamics at 11-13 Weeks of Gestation in Pregnancies Delivering Small for Gestational Age Neonates
}

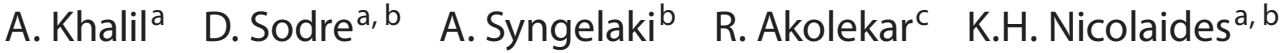 \\ a Department of Fetal Medicine, Institute for Women's Health, University College London Hospitals, \\ ${ }^{b}$ Department of Fetal Medicine, King's College Hospital, London, and 'Department of Fetal Medicine, \\ Medway Maritime Hospital, Kent, UK
}

\section{Key Words}

Pyramid of prenatal care - Preeclampsia - Arterial stiffness • Small for gestational age $\cdot$ Fetal growth restriction $\cdot$ Pulse wave velocity

\begin{abstract}
Objective: To examine aortic systolic blood pressure $\left(\mathrm{SBP}_{\mathrm{Ao}_{0}}\right)$, pulse wave velocity (PWV) and augmentation index (adjusted to a heart rate of 75 beats per minute, Alx-75) at 11-13 weeks' gestation in pregnancies delivering small for gestational age (SGA) neonates with and without preeclampsia (PE). Methods: At $11+0$ to $13+6$ weeks' gestation, maternal history was recorded and PWV, Alx-75, $\mathrm{SBP}_{\mathrm{Ao}}$, uterine artery pulsatility index $(\mathrm{PI})$ and maternal serum pregnancy-associated plasma protein-A (PAPP-A) were measured. We compared women with $(n=337)$ and without $(n=48)$ PE that delivered SGA neonates with unaffected controls $(n=6,429)$. Results: In the SGA group without PE, compared to unaffected controls, there was no significant difference in Alx-75 (1.03 vs. 1.00 multiple of the median, MoM), PWV (0.98 vs. $1.00 \mathrm{MoM}$ ) or $\mathrm{SBP}_{\mathrm{Ao}}$ (1.01 vs. $1.00 \mathrm{MoM}$ ), but uterine artery PI was increased (1.10 vs. $1.00 \mathrm{MoM})$ and PAPP-A decreased (0.85 vs. $1.00 \mathrm{MoM})$. In SGA with $\mathrm{PE}$, compared to unaffected controls, there was increased Alx-75 (1.13 vs. 1.00 MoM),
\end{abstract}

$\mathrm{SBP}_{\mathrm{Ao}}(1.09$ vs. $1.00 \mathrm{MoM})$, uterine artery PI (1.40 vs. $\left.1.00 \mathrm{MoM}\right)$ and decreased PAPP-A (0.72 vs. $1.00 \mathrm{MoM}$ ), but no significant difference in PWV (1.05 vs. $1.00 \mathrm{MoM}$ ). Conclusion: In pregnancies with SGA neonates, impaired placentation is reflected in low PAPP-A and high uterine artery PI at 11-13 weeks' gestation. In the SGA group with $P E$, but not in those without $\mathrm{PE}$, there is increased $\mathrm{SBP}_{\mathrm{Ao}_{0}}$ and $\mathrm{Alx}-75$.

Copyright $\odot 2012$ S. Karger AG, Base

\section{Introduction}

Preeclampsia (PE) and fetal growth restriction (FGR) are major causes of maternal and perinatal mortality and morbidity [1-4]. PE is commonly associated with FGR, particularly early-onset PE [5]. A common pathophysiological mechanism for PE and FGR is impaired placentation, reflected in increased uterine artery pulsatility index (PI) and reduced maternal serum pregnancy-associated plasma protein-A (PAPP-A) [6-8]. However, the determinant of whether a pregnancy with impaired placentation will be complicated by PE or FGR without PE remains unknown. We hypothesized that the development of PE in cases of impaired placentation is, at least in part, a consequence of pre-pregnancy predisposition to

\section{KARGER}

Fax +4161306 1234

E-Mail karger@karger.ch

www.karger.com
(C) 2012 S. Karger AG, Basel

$1015-3837 / 12 / 0324-0231 \$ 38.00 / 0$

Accessible online at:

www.karger.com/fdt
Prof. K.H. Nicolaides

Harris Birthright Research Centre for Fetal Medicine

King's College Hospital

Denmark Hill, London SE5 9RS (UK)

Tel. +44 203299 8256, E-Mail kypros@fetalmedicine.com 
development of chronic hypertension. This is analogous to women with predisposition to type 2 diabetes developing gestational diabetes mellitus under the physiological stress of normal pregnancy.

Evidence for increased maternal predisposition to $\mathrm{PE}$ is provided by studies which report that women who develop $\mathrm{PE}$ are at increased risk of cardiovascular disease and stroke in the subsequent decades [9-12]. Cardiovascular disease is associated with increased arterial stiffness and central aortic systolic blood pressure $\left(\mathrm{SBP}_{\mathrm{Ao}}\right)$ [13-16]. Arterial stiffness can be assessed non-invasively by a simple technique that provides reproducible measurements within a few minutes, and the values of $\mathrm{SBP}_{\mathrm{Ao}}$, pulse wave velocity (PWV) and augmentation index (AIx) have been validated against invasive monitoring [17]. In women with established PE, there is an increase in the values of PWV and AIx, which are measures of arterial stiffness [18-22]. Recent studies have reported that in women who develop $\mathrm{PE}$, increased $\mathrm{SBP}_{\mathrm{Ao}}$ and arterial stiffness are apparent from 11-13 weeks' gestation [2325].

The objective of this study was to examine the hemodynamic indices of $\mathrm{SBP}_{\mathrm{Ao}}$, PWV and AIx and impaired placentation, reflected in increased uterine artery PI and reduced serum PAPP-A at 11-13 weeks' gestation, in pregnancies with and without $\mathrm{PE}$ that result in delivery of small for gestational age (SGA) neonates.

\section{Methods}

This was part of an ongoing prospective screening study for adverse obstetric outcomes in women attending for their routine first trimester ultrasound scan in pregnancy at University College Hospital and King's College Hospital, London, UK, between December 2009 and February 2011. At this visit, which was held at $11+0$ to $13+6$ weeks of gestation, we recorded maternal characteristics and medical history and performed combined screening for aneuploidies by measurement of the fetal crown-rump length and nuchal translucency thickness and maternal serum PAPP-A and free $\beta$-hCG [26]. We also used transabdominal color Doppler ultrasound to visualize the left and right uterine arteries, measured the PI in each vessel and calculated the mean PI [27]. We used the Arteriograph (TensioMed Ltd., Budapest, Hungary) to measure the AIx, PWV and $\mathrm{SBP}_{\mathrm{Ao}}$ in all women who agreed to take part in the study [17]. Written informed consent was obtained from all women. The study was approved by the London-Surrey Borders Research Ethics Committee.

The inclusion criteria for this study were women with a singleton pregnancy and a live fetus identified at the $11^{+0}-13^{+6}$ week scan. We excluded pregnancies with major fetal abnormalities and those ending in termination, miscarriage or fetal death before 24 weeks and those that subsequently developed PE and delivered non-SGA neonates.

\section{Maternal History and Characteristics}

Patients were asked to complete a questionnaire on maternal age, racial origin (Caucasian, African, South Asian, East Asian and mixed), cigarette smoking during pregnancy (yes or no), method of conception (spontaneous or assisted conception requiring the use of ovulation drugs), medical and obstetric history including parity (parous or nulliparous if no previous pregnancies delivering at or after 24 weeks). The questionnaire was then reviewed by a doctor together with each woman. The maternal weight and height were measured and the BMI calculated in kilograms per meter squared.

\section{Outcome Measures}

Details of maternal characteristics and the findings of the 1113 week assessment were recorded in our database. Data on pregnancy outcomes were obtained from the maternity computerized records or the women's general practitioners and were recorded in our database. The neonate was considered SGA if the birth weight was less than the 5 th percentile for gestational age at delivery, using a reference range derived from our population [28]. Neonates with birth weight at or above the 5 th percentile were classified as non-SGA. The diagnosis of PE was made according to the guidelines of the International Society for the Study of Hypertension in Pregnancy [29]. In PE, the systolic blood pressure should be $\geq 140 \mathrm{~mm} \mathrm{Hg}$ and/or the diastolic blood pressure should be $\geq 90 \mathrm{~mm} \mathrm{Hg}$ on at least two occasions $4 \mathrm{~h}$ apart developing after 20 weeks of gestation in previously normotensive women, with proteinuria of $\geq 300 \mathrm{mg}$ in $24 \mathrm{~h}$ or two readings of at least ++ on dipstick analysis of midstream or catheter urine specimens if no 24-hour collection is available.

\section{Arteriograph Measurements}

All measurements were performed in a temperature-controlled room $\left(22^{\circ} \mathrm{C}\right)$ with participants in the supine position. The Arteriograph cuff was then applied on the left arm over the brachial artery for estimation of $\mathrm{SBP}_{\mathrm{Ao}}(\mathrm{mm} \mathrm{Hg}), \mathrm{PWV}(\mathrm{m} / \mathrm{s})$ and $\mathrm{AIx}$ (\%) as previously described [30]. All recordings were made by doctors who had received appropriate training on the use of the Arteriograph. The results of $\mathrm{PWV}$, AIx or $\mathrm{SBP}_{\mathrm{Ao}}$ were not given to the women or their doctors and did not influence the subsequent management of the pregnancies.

\section{Statistical Analysis}

Comparison between the outcome groups was by $\chi^{2}$ test or Fisher's exact test for categorical variables and Mann-Whitney U test for continuous variables, both with post hoc Bonferroni correction. Data are presented as median and interquartile ranges (IQR) for continuous data and as numbers with percentages in parentheses for categorical variables.

The distributions of AIx, PWV and $\mathrm{SBP}_{\mathrm{Ao}}$ were made Gaussian after logarithmic transformation. The normality of distributions was tested using histograms and probability plots after excluding outliers outside three standard deviations. Each value in the SGA and non-SGA groups was expressed as a multiple of the median (MoM) after adjustment for those characteristics found to provide a substantial contribution to the log-transformed value in the multiple regression analysis as previously described [30]. As there was a linear relationship between AIx and heart rate, AIx was adjusted to a heart rate of 75 beats per minute (AIx-75). Pearson correlation analysis was used to examine the association between 
Table 1. Maternal characteristics in the outcome groups

\begin{tabular}{|c|c|c|c|}
\hline Maternal characteristics & $\begin{array}{l}\text { Non-SGA } \\
(n=6,429)\end{array}$ & $\begin{array}{l}\text { SGA without PE } \\
(\mathrm{n}=337)\end{array}$ & $\begin{array}{l}\text { SGA with PE } \\
(\mathrm{n}=48)\end{array}$ \\
\hline Maternal age, years & $32.0(28.2-35.4)$ & $31.1(25.5-34.7)^{*}$ & $31.5(27.1-36.7)$ \\
\hline Maternal weight, kg & $64.0(57.9-72.3)$ & $59.0(53.2-67.0)^{*}$ & $65.9(56.9-75.5)$ \\
\hline Maternal height, m & $1.65(1.60-1.69)$ & $1.62(1.56-1.66)^{*}$ & $1.63(1.58-1.67)^{*}$ \\
\hline Maternal BMI & $23.5(21.4-26.4)$ & $22.6(20.7-25.3)^{*}$ & $24.2(22.1-27.9)$ \\
\hline Caucasian & $4,709(73.2)$ & $189(56.1)$ & $26(54.2)$ \\
\hline African & $928(14.4)$ & $77(22.8)^{*}$ & $18(37.5)^{*}$ \\
\hline South Asian & $379(5.9)$ & $37(11.0)^{*}$ & $3(8.3)$ \\
\hline East Asian & $250(3.9)$ & $21(6.2)$ & 0 \\
\hline Mixed & $163(2.5)$ & $13(3.9)$ & 0 \\
\hline \multicolumn{4}{|l|}{ Parity, n (\%) } \\
\hline Spontaneous & $6,169(96.0)$ & $317(94.1)$ & $44(91.7)$ \\
\hline Ovulation drugs & $260(4.0)$ & $20(5.9)$ & $4(8.3)$ \\
\hline Gestational age at delivery, weeks & $40.1(39.0-40.9)$ & $39.6(38.5-40.7)^{*}$ & $36.7(33.9-38.5)^{*}$ \\
\hline Birth weight percentile & $48.9(29.6-69.1)$ & $2.8(1.4-4.2)^{*}$ & $1.4(0.4-3.2)^{*}$ \\
\hline
\end{tabular}

Values are medians with IQR in parentheses unless otherwise indicated. Comparisons between each outcome group with controls by $\chi^{2}$ test and Fisher's exact test for categorical variables and Mann-Whitney U test with post hoc Bonferroni correction for continuous variables: ${ }^{*} \mathrm{p}<0.025$.

$\log _{10}$ AIx-75 MoM, $\log _{10}$ PWV MoM, $\log _{10} \mathrm{SBP}_{\text {Ao }}$ MoM, $\log _{10}$ uterine artery PI MoM and $\log _{10}$ PAPP-A MoM with gestational age at delivery.

The statistical software package SPSS 16.0 (SPSS Inc., Chicago, Ill., USA) was used for data analyses.

\section{Results}

Maternal PWV, AIx and $\mathrm{SBP}_{\mathrm{Ao}}$ were successfully recorded in 7,653 singleton pregnancies. We excluded 569 $(7.4 \%)$ because they had missing outcome data $(n=449)$, the pregnancies resulted in fetal death or miscarriage before 24 weeks' gestation $(n=60)$ or the pregnancies were terminated for fetal abnormalities or social reasons ( $\mathrm{n}=$ 60). In addition, we excluded 270 cases that subsequently developed PE and delivered non-SGA neonates $(\mathrm{n}=133)$ or gestational hypertension $(\mathrm{n}=137)$. In the remaining 6,814 cases, 337 (5.0\%) without PE subsequently delivered SGA neonates, $48(0.7 \%)$ with PE delivered SGA neonates and 6,429 (94.30\%) delivered non-SGA neonates.

The maternal characteristics of the outcome groups are given in table 1 . In the SGA group without PE, com- pared to the non-SGA group, women were younger, had a lower median maternal height and weight, more women were of African and South Asian racial origin, and there were more nulliparous women who delivered at an earlier gestational age. In the SGA group with $\mathrm{PE}$, compared to the non-SGA group, women had a lower median maternal height, more women were of African racial origin and delivered at an earlier gestational age.

\section{SGA without $P E$}

In the pregnancies without PE that subsequently delivered SGA neonates, compared to those that delivered nonSGA neonates, there was no significant difference in AIx$75, \mathrm{PWV}$ or $\mathrm{SBP}_{\mathrm{Ao}}$, but the uterine artery PI MoM was increased and PAPP-A MoM was decreased (table 2; fig. 1).

There was a significant association of $\log _{10} \mathrm{AIx}-75$ $\operatorname{MoM}(\mathrm{r}=-0.122, \mathrm{p}=0.025), \log _{10} \mathrm{SBP}_{\mathrm{Ao}} \mathrm{MoM}(\mathrm{r}=-0.127$, $\mathrm{p}=0.019)$ and $\log _{10}$ PAPP-A MoM $(\mathrm{r}=0.134, \mathrm{p}=$ 0.015 ; fig. 2) with gestational age at delivery but not of $\log _{10} \mathrm{PWV}$ MoM $(\mathrm{r}=-0.004, \mathrm{p}=0.937)$ or $\log _{10}$ uterine artery PI MoM ( $\mathrm{r}=0.056, \mathrm{p}=0.316$; fig. 2$)$ with gestational age at delivery. 


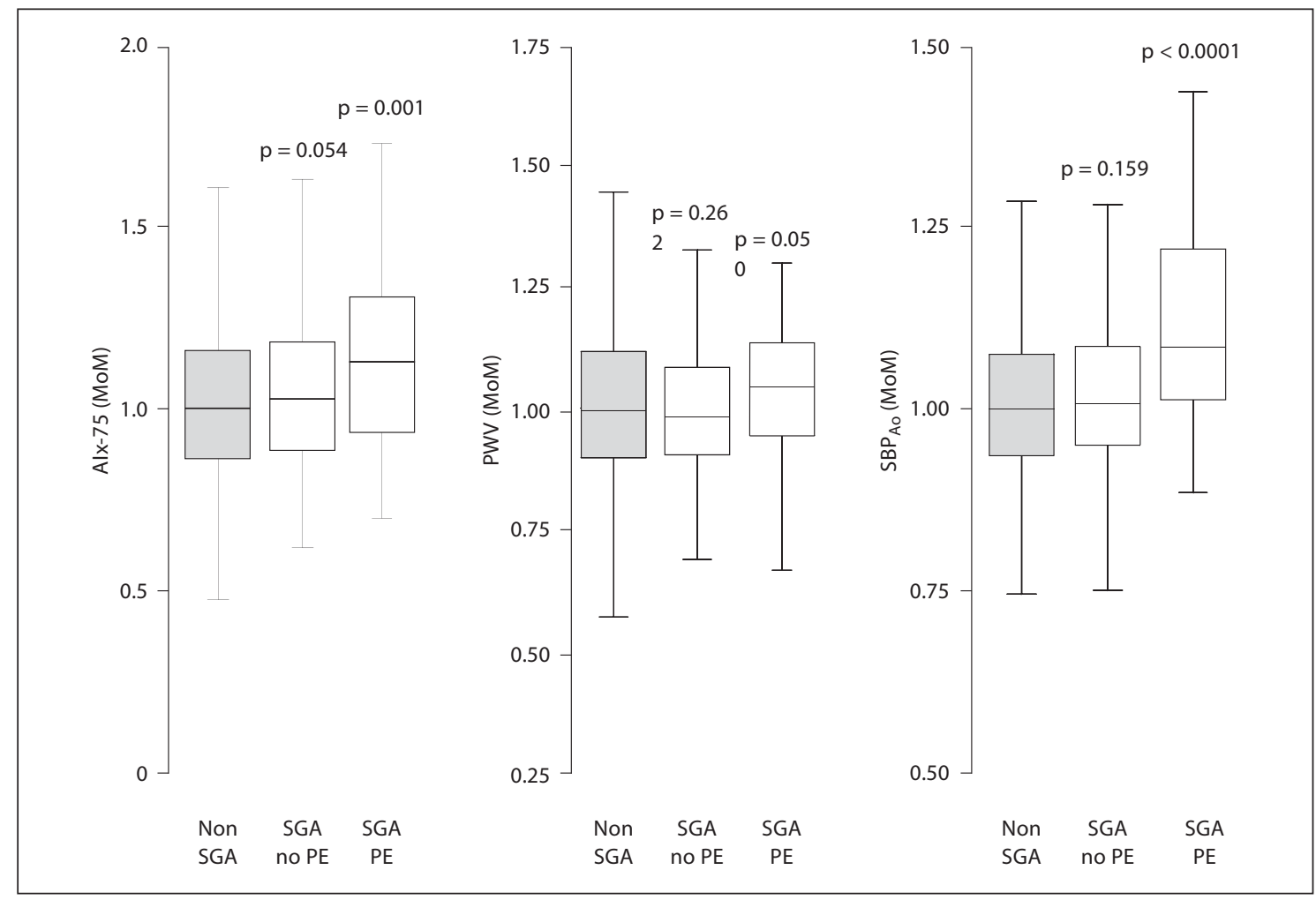

Fig. 1. Box and whisker plots of AIx-75 MoM, PWV MoM, and central SBP MoM in pregnancies with and without PE that subsequently delivered SGA neonates, compared to those that did not. The horizontal line in the box represents the median, the box represents the interquartile range and the whiskers indicate the minimum and maximum values.

Table 2. AIx, PWV and central $\mathrm{SBP}_{\mathrm{Ao}}$ in pregnancies with and without PE that delivered SGA neonates compared to those that did not

\begin{tabular}{|c|c|c|c|}
\hline Variable & $\begin{array}{l}\text { Non-SGA } \\
(\mathrm{n}=6,429)\end{array}$ & $\begin{array}{l}\text { SGA without PE } \\
(\mathrm{n}=337)\end{array}$ & $\begin{array}{l}\text { SGA with PE } \\
(\mathrm{n}=48)\end{array}$ \\
\hline \multicolumn{4}{|l|}{ AIx } \\
\hline$\%$ & $10.5(5.4-16.6)$ & $12.5(6.8-18.8)$ & $14.5(7.9-22.0)$ \\
\hline MoM & $1.00(0.87-1.16)$ & $1.03(0.89-1.19)$ & $1.13(0.93-1.32)^{*}$ \\
\hline \multicolumn{4}{|l|}{ PWV } \\
\hline $\mathrm{m} / \mathrm{s}$ & $6.56(5.83-7.42)$ & $6.33(5.76-7.05)$ & $7.23(6.54-7.77)$ \\
\hline MoM & $1.00(0.90-1.12)$ & $0.98(0.90-1.09)$ & $1.05(0.94-1.14)$ \\
\hline \multicolumn{4}{|c|}{ Central SBP } \\
\hline $\mathrm{mm}$ & $108(101-117)$ & $108(101-116)$ & $119(112-132)$ \\
\hline MoM & $1.00(0.94-1.08)$ & $1.01(0.95-1.09)$ & $1.09(1.01-1.22)^{*}$ \\
\hline \multicolumn{4}{|l|}{ PAPP-A } \\
\hline $\mathrm{IU} / \mathrm{l}$ & $2.90(1.92-4.50)$ & $2.77(1.67-4.96)$ & $2.16(1.08-8.07)$ \\
\hline MoM & $1.00(0.79-1.42)$ & $0.85(0.56-1.25)^{*}$ & $0.72(0.53-0.98)^{*}$ \\
\hline \multicolumn{4}{|c|}{ Uterine artery PI } \\
\hline Unit & $1.71(1.39-2.07)$ & $1.93(1.50-2.30)$ & $2.36(2.12-2.79)$ \\
\hline MoM & $1.00(0.82-1.20)$ & $1.10(0.86-1.32)^{*}$ & $1.40(1.17-1.64)^{*}$ \\
\hline
\end{tabular}

Values are medians and IQR in parentheses. Comparisons between outcome groups by Mann-Whitney U test and post hoc Bonferroni correction: corrected significance value ${ }^{*} \mathrm{p}<0.025$. 


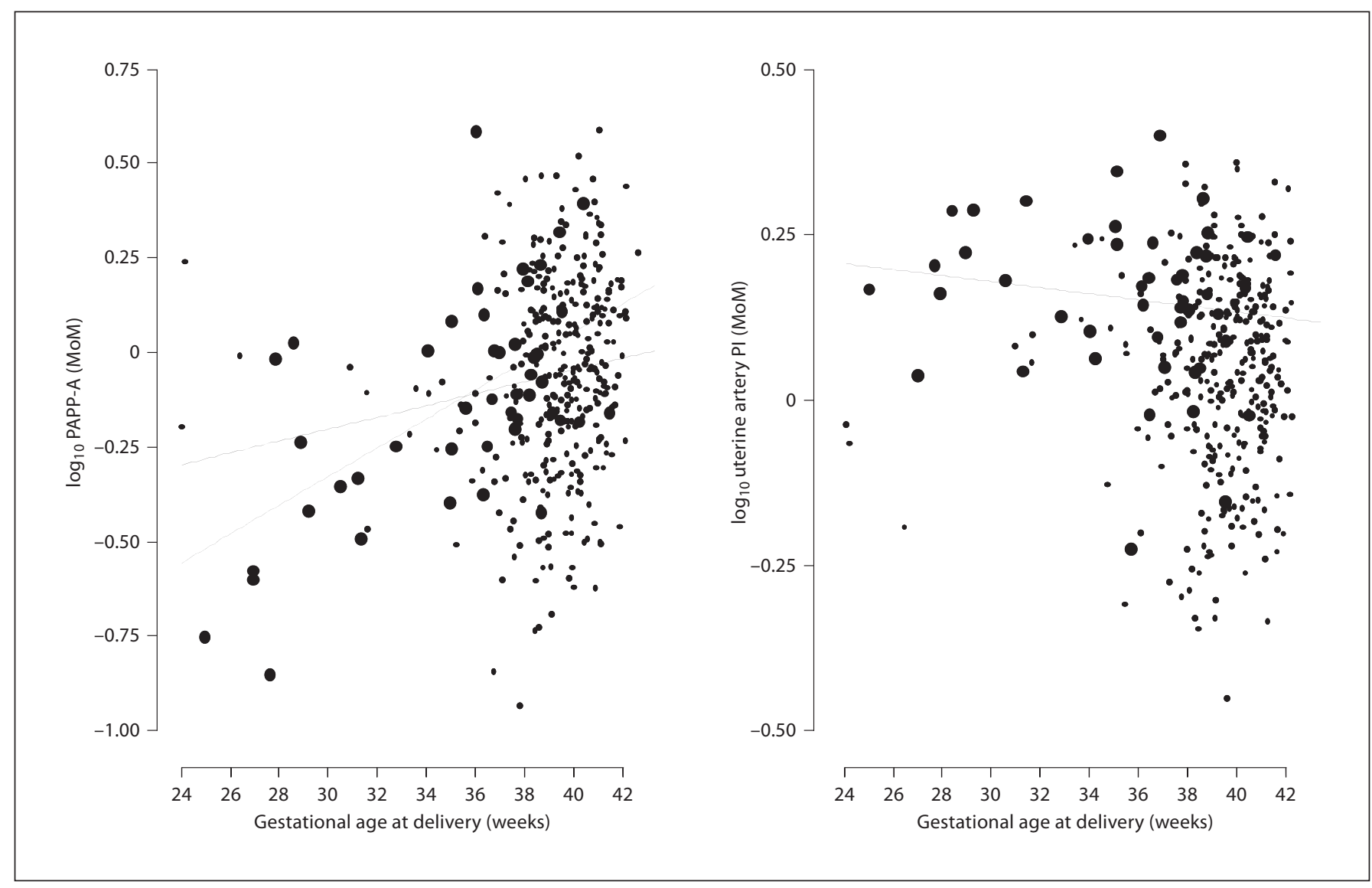

Fig. 2. Scatter plot demonstrating the association of $\log _{10}$ PAPP-A MoM (left) and $\log _{10}$ uterine artery PI MoM (right) with gestational age at delivery in women without PE that subsequently delivered SGA neonates (closed circles and solid regression line) and those with PE that delivered SGA neonates (open circles and interrupted regression line).

SGA with $P E$

In the pregnancies with $\mathrm{PE}$ that subsequently delivered SGA neonates, compared to those that delivered non-SGA neonates, the AIx-75, $\mathrm{SBP}_{\mathrm{Ao}}$ and uterine artery PI MoM were increased and PAPP-A MoM was decreased, but the PWV was not significantly different (table 2; fig. 1).

There was a significant association of $\log _{10}$ uterine artery PI MoM and $\log _{10}$ PAPP-A MoM with gestational age at delivery $(\mathrm{r}=-0.333, \mathrm{p}=0.022$ and $\mathrm{r}=0.567, \mathrm{p}<$ 0.0001 , respectively; fig. 2) but not of $\log _{10} \mathrm{AIx}-75 \mathrm{MoM}$, $\log _{10} \mathrm{PWV} \mathrm{MoM}$ or $\log _{10} \mathrm{SBP}_{\mathrm{Ao}} \mathrm{MoM}$ with gestational age at delivery $(\mathrm{r}=0.0004, \mathrm{p}=0.998 ; \mathrm{r}=0.078, \mathrm{p}=0.599$ and $\mathrm{r}=-0.053, \mathrm{p}=0.720$, respectively).

\section{Discussion}

The findings of this study demonstrate that in pregnancies delivering SGA neonates, there is evidence of impaired placentation reflected in low PAPP-A and high uterine artery PI at 11-13 weeks' gestation. In the SGA group with $\mathrm{PE}$, but not in those without $\mathrm{PE}$, there is increased $\mathrm{SBP}_{\mathrm{Ao}}$ and arterial stiffness. The findings are compatible with our hypothesis that in pregnancies with impaired placentation, one of the determinants of whether there will be development of PE or SGA without PE is pre-existing susceptibility to cardiovascular disease reflected in increased $\mathrm{SBP}_{\mathrm{Ao}}$ and $\mathrm{AIx}-75$.

Impaired trophoblastic invasion of the maternal spiral arteries leads to placental ischemia and the release of inflammatory factors which cause endothelial cell activation and damage [31,32]. There is also evidence that 
women who are predisposed to cardiovascular disease prior to pregnancy are likely to have a degree of generalized endothelial dysfunction and low-grade inflammation, manifested as increased arterial stiffness [33-35]. It is possible that the clinical manifestations of $\mathrm{PE}$ are the consequence of a synergy of two independent factors, placental ischemia and predisposition to cardiovascular disease, producing an exaggerated degree of endothelial dysfunction.

The strengths of this study include the large number of subjects examined and the narrow gestational age range of 11-13 weeks for the investigation, which is emerging as the first clinical visit in pregnancy for assessment of patient-specific risks for a wide range of pregnancy complications [36]. Robust outcome data were collected prospectively, the diagnosis of PE was ascertained from the patients' records, and we controlled for potential confounders that might affect arterial stiffness and $\mathrm{SBP}_{\mathrm{Ao}}$. The birth weight percentiles were calculated using a reference range derived from our population [28]. A limitation of the study is the lack of longitudinal data before pregnancy, during pregnancy and postnatally in women who had SGA with PE in order to evaluate whether increased arterial stiffness and $\mathrm{SBP}_{\text {Ao }}$ pre-existed and/ or persisted beyond the pregnancy.

SGA was defined as neonatal birth weight less than the 5th percentile for gestational age at delivery, using a reference range derived from our population [28]. This group might include constitutionally small babies, as well as growth-restricted fetuses. We could not study the changes in these two subgroups separately. The study was based on screening at 12 weeks and subsequent outcome with retrospective diagnosis of SGA based on birth weight. We did not examine all these women in the third trimester and therefore we do not have Doppler measurements in the third trimester in the majority of the SGA cases.

Evidence that women who develop PE are at increased risk of cardiovascular disease and stroke in the subsequent decades is derived from large epidemiological studies [9-12]. There is also evidence from healthy non-pregnant individuals that increased arterial stiffness and $\mathrm{SBP}_{\mathrm{Ao}}$ are associated with subsequent development of cardiovascular disease and death [37-41]. It is therefore possible that, firstly, the abnormal cardiovascular findings in early pregnancy in women who subsequently develop PE may actually predate conception and, secondly, development of $\mathrm{PE}$ in cases of impaired placentation is, at least in part, a consequence of pre-pregnancy predisposition to development of chronic hypertension.
In pregnancies complicated by SGA without PE, there is evidence of impaired placentation, but in these cases, we found that arterial stiffness and $\mathrm{SBP}_{\mathrm{Ao}}$ at 11-13 weeks are normal. Epidemiological studies reported that the long-term risk of mortality from cardiovascular disease was inversely related to the birth weight of offspring [42, 43]. However, these studies did not present separate data for SGA with and without PE and it is therefore not possible to determine whether the observed increase in mortality could be attributed to the subgroup of SGA with associated PE. A retrospective cohort study of 129,290 women reported that the hazard ratio for hospital admission or death from ischemic heart disease was 1.9 in those who delivered a baby in the lowest birth weight quintile for gestational age in the absence of $\mathrm{PE}$ [44]. A nationwide Swedish study on 923,686 women and their first singleton births between 1983 and 2005 reported that the increase in hazard ratio for maternal hospitalization or death from cardiovascular disease, adjusted for pregnancy characteristics including PE, was modest $(1.83,95 \%$ CI $1.59-$ 2.11) and confined to those with very small infants whose birth weight was below the 2nd percentile [45]. Suggested possible explanations for such a link between birth of an SGA neonate and increased susceptibility to cardiovascular disease include environmental, lifestyle or common genetic risk factors [44].

In pregnancies delivering SGA neonates, with or without coincidence of PE, there is evidence of impaired placentation. Similarly, epidemiological studies suggest that both women who develop PE and those who deliver SGA neonates in the absence of $\mathrm{PE}$ are at increased risk of death from cardiovascular disease. Our finding that in women who develop PE, but not in those delivering SGA neonates in the absence of $\mathrm{PE}$, there is evidence of increased $\mathrm{SBP}_{\mathrm{Ao}}$ and arterial stiffness, suggests that the mechanisms underlying the increased risk of cardiovascular disease in the two types of pregnancies may be different.

\section{Acknowledgement}

This study was supported by a grant from the Fetal Medicine Foundation (Charity No. 1037116). 


\section{References}

1 World Health Organization: Make Every Mother and Child Count. World Health Report, 2005. Geneva, World Health Organization, 2005.

-2 Cantwell R, Clutton-Brock T, Cooper G, Dawson A, Drife J, Garrod D, Harper A, Hulbert D, Lucas S, McClure J, Millward-Sadler H, Neilson J, Nelson-Piercy C, Norman J, O'Herlihy C, Oates M, Shakespeare J, de Swiet M, Williamson C, Beale V, Knight M, Lennox C, Miller A, Parmar D, Rogers J, Springett A: Saving mothers' lives: reviewing maternal deaths to make motherhood safer: 2006-2008. The Eighth Report of the Confidential Enquiries into Maternal Deaths in the United Kingdom. BJOG 2011;118(suppl 1):1-203.

-3 McIntire DD, Bloom SL, Casey BM, Leveno $\mathrm{KJ}$ : Birth weight in relation to morbidity and mortality among newborn infants. N Engl J Med 1999;340:1234-1238.

-4 Alexander GR, Kogan M, Bader D, Carlo W, Allen M, Mor J: US birth weight/gestational age-specific neonatal mortality: 1995-1997 rates for whites, Hispanics, and blacks. Pediatrics 2003;111:e61-e66.

$\checkmark 5$ Yu CK, Khouri O, Onwudiwe N, Spiliopoulos Y, Nicolaides KH: Fetal Medicine Foundation Second-Trimester Screening Group. Prediction of pre-eclampsia by uterine artery Doppler imaging: relationship to gestational age at delivery and small-for-gestational age. Ultrasound Obstet Gynecol 2008; 31:310-313.

-6 Kaufmann P, Black S, Huppertz B: Endovascular trophoblast invasion: implications for the pathogenesis of intrauterine growth retardation and preeclampsia. Biol Reprod 2003;69:1-7.

7 Akolekar R, Syngelaki A, Sarquis R, Zvanca $\mathrm{M}$, Nicolaides KH: Prediction of early, intermediate and late pre-eclampsia from maternal factors, biophysical and biochemical markers at 11-13 weeks. Prenat Diagn 2011; 3:66-74.

8 Karagiannis G, Akolekar R, Sarquis R, Wright D, Nicolaides KH: Prediction of small-for-gestation neonates from biophysical and biochemical markers at 11-13 weeks. Fetal Diagn Ther 2011;29:148-154.

-9 Irgens HU, Reisaeter L, Irgens LM, Lie RT: Long term mortality of mothers and fathers after pre-eclampsia: population based cohort study. BMJ 2001;323:1213-1217.

10 Smith GC, Pell JP, Walsh D: Pregnancy complications and maternal risk of ischaemic heart disease: a retrospective cohort study of 129,290 births. Lancet 2001;357:2002-2006.

- 11 Ray JG, Vermeulen MJ, Schull MJ, Redelmeier DA: Cardiovascular health after maternal placental syndromes (CHAMPS): population-based retrospective cohort study. Lancet 2005;366:1797-1803.
12 Bellamy L, Casas JP, Hingorani AD, Williams DJ: Pre-eclampsia and risk of cardiovascular disease and cancer in later life: systematic review and meta-analysis. BMJ 2007; 335:974-986.

13 Terai M, Ohishi M, Ito N, Takagi T, Tatara Y, Kaibe M, Komai N, Rakugi H, Ogihara T: Comparison of arterial functional evaluations as a predictor of cardiovascular events in hypertensive patients: the Non-Invasive Atherosclerotic Evaluation in Hypertension (NOAH) study. Hypertens Res 2008;31: 1135-1145.

14 Roman MJ, Devereux RB, Kizer JR, Lee ET, Galloway JM, Ali T, Umans JG, Howard BV: Central pressure more strongly relates to vascular disease and outcome than does brachial pressure: the Strong Heart Study. Hypertension 2007;50:197-203.

15 O'Rourke MF: Arterial pressure waveforms in hypertension. Minerva Med 2003;94:229_ 250.

16 Laurent S, Cockcroft J, Van Bortel L, Boutouyrie P, Giannattasio C, Hayoz D, Pannier B, Vlachopoulos C, Wilkinson I, StruijkerBoudier Hl; European Network for Non-invasive Investigation of Large Arteries: Expert consensus document on arterial stiffness: methodological issues and clinical applications. Eur Heart J 2006;27:25882605

17 Horváth IG, Németh A, Lenkey Z, Alessandri N, Tufano F, Kis P, Gaszner B, Cziráki A: Invasive validation of a new oscillometric device (Arteriograph) for measuring augmentation index, central blood pressure and aortic pulse wave velocity. J Hypertens 2010; 28:2068-2075.

18 Elvan-Taspinar A, Franx A, Bots ML, Bruinse HW, Koomans HA: Central hemodynamics of hypertensive disorders in pregnancy. Am J Hypertens 2004;17:941-946.

19 Spasojevic M, Smith SA, Morris JM, Gallery ED: Peripheral arterial pulse wave analysis in women with pre-eclampsia and gestational hypertension. BJOG 2005;112:1475-1478.

20 Khalil A, Jauniaux E, Harrington K: Antihypertensive therapy and central hemodynamics in women with hypertensive disorders in pregnancy. Obstet Gynecol 2009;113:646654.

21 Robb AO, Mills NL, Din JN, Smith IB, Paterson F, Newby DE, Denison FC: Influence of the menstrual cycle, pregnancy, and pre-eclampsia on arterial stiffness. Hypertension 2009;53:952-958.

22 Kaihura C, Savvidou MD, Anderson JM, McEniery CM, Nicolaides KH: Maternal arterial stiffness in pregnancies affected by pre-eclampsia. Am J Physiol Heart Circ Physiol 2009;297:H759-H764.

23 Khalil AA, Cooper DJ, Harrington KF: Pulse wave analysis: a preliminary study of a novel technique for the prediction of pre-eclampsia. BJOG 2009;116:268-276.
24 Khalil A, Cowans NJ, Spencer K, Goichman $\mathrm{S}$, Meiri $\mathrm{H}$, Harrington K: First-trimester markers for the prediction of pre-eclampsia in women with a-priori high risk. Ultrasound Obstet Gynecol 2010;35:671-679.

25 Khalil A, Akolekar R, Syngelaki A, Elkhaouli M, Nicolaides KH: Maternal hemodynamics at 11-13 weeks' gestation and the risk of pre-eclampsia. Ultrasound Obstet Gynecol 2012;40:28-34.

26 Kagan KO, Wright D, Spencer K, Molina FS, Nicolaides KH: First-trimester screening for trisomy 21 by free beta-human chorionic gonadotropin and pregnancy-associated plasma protein-A: impact of maternal and pregnancy characteristics. Ultrasound Obstet Gynecol 2008;31:493-502.

27 Plasencia W, Maiz N, Bonino S, Kaihura C, Nicolaides KH: Uterine artery Doppler at $11+0$ to $13+6$ weeks in the prediction of preeclampsia. Ultrasound Obstet Gynecol 2007; 30:742-749.

28 Poon LC, Karagiannis G, Staboulidou I, Shafiei A, Nicolaides KH: Reference range of birth weight with gestation and first-trimester prediction of small-for-gestation neonates. Prenat Diagn 2011;31:58-65.

29 Brown MA, Lindheimer MD, de Swiet M Van Assche A, Moutquin JM: The classification and diagnosis of the hypertensive disorders of pregnancy: statement from the International Society for the Study of Hypertension in Pregnancy (ISSHP). Hypertens Pregnancy 2001;20:IX-XIV.

30 Khalil A, Akolekar R, Syngelaki A, Elkhaouli M, Nicolaides KH: Maternal hemodynamics in normal pregnancies at 11-13 weeks' gestation. Fetal Diagn Ther 2012, in press.

31 Redman CW, Sacks GP, Sargent IL: Preeclampsia: an excessive maternal inflammatory response to pregnancy. Am J Obstet Gynecol 1999;80:499-506.

-32 Granger JP, Alexander BT, Llinas MT, Bennett WA, Khalil RA: Pathophysiology of hypertension during preeclampsia linking placental ischemia with endothelial dysfunction. Hypertension 2001;38:718-722.

-33 Wilkinson IB, Hall IR, McCallum H, Mackenzie IS, McEniery CM, van der Arend BJ, Shu YE, MacKay LS, Webb DJ, Cockcroft JR: Pulse wave analysis: clinical evaluation of a non invasive, widely applicable method for assessing endothelial function. Arterioscler Thromb Vasc Biol 2002;22:147-152.

-34 Wilson AM, O'Neal D, Nelson CL, Prior DL, Best JD, Jenkins AJ: Comparison of arterial assessments in low and high vascular disease risk groups. Am J Hypertens 2004;17:285291.

35 Lane HA, Smith JC, Davies JS: Noninvasive assessment of preclinical atherosclerosis. Vasc Health Risk Manag 2006;2:19-30.

36 Nicolaides KH: Turning the pyramid of prenatal care. Fetal Diagn Ther 2011;29:183196. 
\37 Maldonado J, Pereira T, Polónia J, Silva JA, Morais J, Marques M; participants in the EDIVA Project: Arterial stiffness predicts cardiovascular outcome in a low-to-moderate cardiovascular risk population: the EDIVA (Estudo de DIstensibilidade VAscular) project. J Hypertens 2011;29:669-675.

38 Willum-Hansen T, Staessen JA, Torp-Pedersen C, Rasmussen S, Thijs L, Ibsen H, Jeppesen J: Prognostic value of aortic pulse wave velocity as index of arterial stiffness in the general population. Circulation 2006;113: 664-670.

39 Shokawa T, Imazu M, Yamamoto H, Toyofuku M, Tasaki N, Okimoto T, Yamane K, Kohno N: Pulse wave velocity predicts cardiovascular mortality: findings from the $\mathrm{Ha}$ waii-Los Angeles-Hiroshima study. Circ J 2005;69:259-264.
40 Mattace-Raso FU, van der Cammen TJ, Hofman A, van Popele NM, Bos ML, Schalekamp MA, Asmar R, Reneman RS, Hoeks AP, Breteler MM, Witteman JC: Arterial stiffness and risk of coronary heart disease and stroke: the Rotterdam Study. Circulation 2006;113: 657-663.

41 Meaume S, Benetos A, Henry OF, Rudnichi A, Safar ME: Aortic pulse wave velocity predicts cardiovascular mortality in subjects $>70$ years of age. Arterioscler Thromb Vasc Biol 2001;21:2046-2050.
2 Smith GD, Harding S, Rosato M: Relation between infants' birth weight and mothers' mortality: prospective observational study. BMJ 2000;320:839-840.

43 Davey Smith G, Whitley E, Gissler M, Hemminki E: Birth dimensions of offspring, premature birth, and the mortality of mothers. Lancet 2000;356:2066-2067.

44 Smith GC, Pell JP, Walsh D: Pregnancy complications and maternal risk of ischaemic heart disease: a retrospective cohort study of 129,290 births. Lancet 2001;357:2002-2006.

45 Bonamy AK, Parikh NI, Cnattingius S, Ludvigsson JF, Ingelsson E: Birth characteristics and subsequent risks of maternal cardiovascular disease: effects of gestational age and fetal growth. Circulation 2011;124:28392846. 